\title{
Cooperativa de cuidados: de la prestación económica de asistencia personal hacia la colectivización de las personas cuidadoras ${ }^{1}$
}

\author{
Liseth Díaz Molina \\ Gezki, Universidad del País Vasco (UPV/EHU) \\ lisethdelsocorro.diaz@ehu.eus
}

\section{Enekoitz Etxezarreta Etxarri}

Facultad de Economía y Empresa, Universidad del País Vasco (UPV/EHU) enekoitz.etxezarreta@ehu.eus

\section{Mertxe Larrañaga Sarriegui}

Facultad de Economía y Empresa, Universidad del País Vasco (UPV/EHU)

mertxe.larranaga@ehu.eus

\begin{abstract}
Ikerlan honek zaintza lanen testuingurua aztertu eta lan elkartuko kooperatibak bezalako ekintzailetza kolektiboko prozesuak sustatzeko beharrezkoak diren baliabideak azaleratzea du helburu. Eskuartean duzun lan honek GEZKI Institutuak (UPV/EHU) eginiko ikerketan jasotzen diren zaintzaileen kolektiboak dituen beharren diagnostikoaren emaitzak aurkezten ditu eta LPPEren bitartez zaintzen kolektibizaziorako proposamen bat egiten da. Honek zaintza langileak antolatzeari eta euren lan baldintzen hobekuntzari, behin-behinekotasunaren aurkako borrokari eta kalitatezko enpleguak lortzeari ateak irekiko lioke, besteak beste. Proiektu hau ekonomia feministaren oinarri teorikoan sostengatzen da, zeinak batez ere emakumeek egiten dituzten zaintza lanak ikusarazi eta balioan jartzeko esfortzu handia egin duen. Gainera, pertsonek bizitzaren etapa ezberdinetan beharrezkoa duten interdependentzia azaleratu du teoria honek.
\end{abstract}

\section{GAKO-HITZAK:}

Zaintza informalak, zaintzaileak, beharrak, menpekotasuna, kolektibizazioa.
En este artículo se analiza el contexto y los recursos para proponer impulsar procesos de emprendimiento mediante organizaciones más igualitarias como son las cooperativas de trabajo asociado. El trabajo que aquí presentamos expone los resultados del diagnóstico de necesidades del colectivo de cuidadoras, estudio que fue elaborado por Gezki (UPV/EHU) y realiza una propuesta de colectivización de los cuidados a través de la Prestación Económica de Asistencia Personal (PEAP). Ello abriría una vía para que las profesionales del cuidado consigan organizarse y mejorar sus condiciones laborales, luchar contra la temporalidad y lograr generar empleo de calidad, entre otros beneficios. Este proyecto se sustenta sobre la base teórica de la economía feminista que ha hecho un esfuerzo considerable por visibilizar y valorar los trabajos de cuidados desarrollados sobre todo por mujeres, teoría que subraya también la interdependencia de las personas a lo largo de toda la vida.

\section{Palabras Clave:}

Cuidados informales, cuidadoras, necesidades, dependencia, colectivización. 


\section{Introducción}

Los países occidentales están inmersos en un proceso de envejecimiento que parece imparable. Así, el 19,5\% de la población de la Unión Europea tiene en el año 2017 más de 65 años y el 5,5\% supera los 80 años. El porcentaje de mayores de 80 años es especialmente elevado en los países del sur de Europa: es del 6,8\% en Italia, 6,7\% en Grecia, 6,2 \% en España y $6,1 \%$ en Portugal. Así pues, el cuidado y atención de las personas mayores está en la agenda de los gobiernos y es, al mismo tiempo, objeto de debate y preocupación social por múltiples motivos.

Los trabajos de cuidados han sido históricamente responsabilidad de las mujeres y cuando se realizan de manera remunerada también son llevados a cabo por mujeres, casi siempre por mujeres pobres y a menudo por mujeres migrantes. Como ejemplo, basta señalar que según los últimos datos de la Encuesta de Población Activa (EPA), en el Estado español había, a finales de $2017,470.000$ personas empleadas domésticas, de las que el $98 \%$ son mujeres.

El objeto de este artículo es explorar las ventajas que las cooperativas de trabajo asociado pueden ofrecer en la resolución de las necesidades que el colectivo de trabajadoras de hogar puedan tener, así como de las necesidades de los personas dependientes. La base de este trabajo es la investigación de carácter cualitativo² desarrollada por Gezki - Instituto de Derecho Cooperativo y Economía Social-en Gipuzkoa a lo largo de 2015 y 2016. En el proyecto se elaboró un diagnóstico de las necesidades de las trabajadoras dedicadas al cuidado de dependientes y se planteó si ofreciendo un servicio conjunto se podrían mejorar sus condiciones laborales y evitar situaciones de precariedad. La investigación se desarrolló en el marco de la economía social y solidaria, que posee un gran potencial innovador y puede ser una alternativa capaz de dar respuesta a las necesidades del sector de los cuidados personales.

El artículo se estructura de la siguiente manera: en primer lugar, se aborda el marco teórico del estudio y para ello se parte de la economía feminista. A continuación se abordan el marco jurídico del empleo de hogar y la realidad de las prestaciones de dependencia en Gipuzkoa. Esto nos servirá para enmarcar el estudio cualitativo al que hemos aludido con anterioridad: tras presentar los objetivos y la metodología, se abordarán los resultados y la discusión sobre la colectivización de las cuidadoras. Cerraremos el estudio con unas breves conclusiones.

${ }^{2}$ El título del proyecto es "Gipuzkoako zaintza esparruan Ekonomia Sozial eta Solidarioko ekimenak martxan jartzeko oinarriak" ("Bases para la puesta en marcha de iniciativas de la Economía social y Solidaria en el marco de los cuidados en Gipuzkoa"). Financiado por el Departamento de Política Social, de la Diputación Foral de Gipuzkoa.

\section{La economía de cuidados: sector clave para sostener la vida}

Hay trabajos universales que han existido siempre y en todo lugar. Estos trabajos han sido denominados de diferentes maneras: trabajos de subsistencia, de mantenimiento, domésticos y de cuidados, siendo este último el término más utilizado en la actualidad. "La economía de cuidados es un enfoque analítico y político, construido desde la economía feminista, combina una crítica a la economía convencional y la propuesta de alternativas para colocar como prioritario y hacer viable el cuidado humano en condiciones de igualdad, para reconocer las dimensiones reproductivas de la economía que son indisociables de las productivas" (León, 2009). La economía feminista ha hecho un esfuerzo considerable por visibilizar y valorar los trabajos de cuidados desarrollados sobre todo por mujeres de manera gratuita. Si bien en sus inicios la construcción teórica de los cuidados se centró en los trabajos no remunerados desarrollados en el hogar (Graham, 1983), pronto esta visión estrecha de los cuidados fue contestada por estudios procedentes de la política social (Carrasquer, 2013).

La economía de cuidados cuestiona también uno de los mitos de la economía convencional, el del homo economicus como sujeto autónomo, siempre activo en el mercado, absolutamente egoísta y racional. Frente a ello, la economía feminista subraya que todos los seres humanos somos interdependientes y, por tanto, necesitados de cuidados.

La inicial definición restrictiva de los cuidados fue contestada al señalar que los cuidados no se circunscriben al hogar, ni se orientan solo a la crianza o al cuidado de las personas adultas sanas del entorno familiar. Así, se abrió el concepto de cuidados hacia la dependencia y hacia los cuidados, informales o no, prodigados en la esfera pública (Parker, 1981; Ungerson, 1983, 2005).

La interdependencia se da a lo largo de toda la vida pero es evidente que la necesidad de atención y de cuidados es especialmente importante en determinados momentos de la vida, principalmente al inicio y al final, así como en momentos concretos o, en el caso de personas con diversidad funcional, a lo largo de toda la vida. Para las sociedades occidentales, un reto inaplazable es garantizar el cuidado de mayores dependientes (Jubeto, Larrañaga y Rodríguez, 2017). De hecho, los cuidados de las personas mayores, se encuentran en el centro de la atención pública de los países de la OCDE (OCDE, 2015).

En palabras de Cristina Carrasco, "el envejecimiento demográfico, junto a la cada vez mayor participación laboral de las mujeres, ha llevado a una situación crítica, puesto que la oferta de trabajo de las mujeres no era infinita, como parece que se presuponía. Una situación crítica en relación al cuidado de las personas, básicamente, de las personas mayores muy dependientes que requieren presencia 
constante de otra persona adulta" (Carrasco, 2013: 46). Así pues, en la crisis de asistencia y de cuidados han incidido dos tendencias: la primera tendencia se refiere al aumento de la esperanza de vida y por consiguiente de la población anciana, pero que no se ha acompañado con un aumento de los servicios de asistencia a las personas mayores. La segunda tendencia se refiere al aumento del número de mujeres empleadas de manera asalariada fuera de los hogares, lo que ha supuesto una reducción de la contribución de estas mujeres a la reproducción de sus familias (Carrasco, 2013).

A estas dos tendencias, Silvia Federici añade una tercera, la referida al continuo "proceso de crecimiento urbano y de gentrificación de los barrios obreros, que han destruido las redes sociales y los diversos modelos de apoyo mutuo en los que podían confiar las personas mayores que se encontraban viviendo solas [...]. La consecuencia de todo ello es que para una gran parte de estas personas los efectos positivos de la mayor esperanza de vida se convierten en efectos negativos, transformándose en soledad, exclusión social e incremento de su vulnerabilidad frente a abusos físicos y psíquicos" (Federici, 2013).

El concepto de los cuidados ha experimentado una importante evolución desde su conceptualización inicial hasta que Mary Daly y Jane Lewis (2000), propusieron la noción de modelo de "organización social del cuidado" (social care) como categoría de análisis y así poder adentrarse en el conjunto de las actividades y las relaciones que intervienen en la satisfacción de las necesidades físicas y emocionales de las personas dependientes, así como de los marcos normativos, económicos y sociales donde se asignan y se desarrollan (Martínez Herrero, 2017). Esta reconceptualización de los cuidados permitió salir de una visión de los cuidados focalizada en "lo femenino" y trasladarla hacia la discusión sobre las necesidades y la provisión de bienestar. En esta propuesta, los cuidados son un trabajo socialmente organizado en el que participan distintos grupos, instituciones y espacios sociales, que se articula y distribuye de acuerdo a distintos patrones socioculturales y económicos (Carrasaquer, 2013).

Precisamente, otra forma de abordar el análisis de la provisión de cuidados es hacerlo a través de las instituciones, actores y sectores participantes. Es lo que hace Shashra Razavi (2007) desde la noción del “diamante del cuidado", representación geométrica de la organización social del cuidado a partir de cuatro ángulos: el Estado, el mercado, la familia y la comunidad. A través de esta arquitectura del diamante, la autora analiza no solo las políticas sociales orientadas a cubrir las necesidades de cuidado intenso, es decir, los cuidados a menores, mayores y personas con enfermedades crónicas o con discapacidades físicas o mentales, sino también las provisiones de cuidado intermedias, como el trabajo doméstico realizado por familiares a cambio de una remuneración, o los servicios proporcionados por el mercado pero que cuentan con ayudas públicas. Además, permite estudiar la cuestión tanto desde el lado de quienes reciben cuidados como desde quienes los proveen (Martínez, 2017).

Está claro que en este diamante el Estado tiene un papel crucial, en tanto que "habla" mediante sus leyes y, en este sentido, tiene eficacia simbólica (Gaba y Salvo, 2016). Además, aunque parezca contradictorio, la implicación del sector público en los cuidados puede potenciar el mercado, ya que gran parte de las políticas se centra en prestaciones económicas o en la subcontratación de servicios (Keller, 2017).

En este artículo centramos el análisis en la provisión de cuidados a personas dependientes de manera remunerada. Las situaciones de dependencia se definen como "la falta o pérdida de autonomía personal (física, psicológica y/o social), que precisa de apoyo para el desarrollo de las actividades elementales de la vida diaria, como puede ser vestirse y desvestirse, preparar comidas o administrar dinero, entre otras" (Minguela y Camacho, 2015). La existencia de limitaciones crea una necesidad de apoyo y cuidado personal que puede ser de tres tipos:

- Apoyo informal: "El cuidado y atención que se dispensa de manera altruista a las personas que presentan algún grado de discapacidad o dependencia" (lo conforman los familiares, otros agentes y redes distintas de los servicios formalizados de atención).

- Apoyo formal: “Dispensado por los servicios sociales y sanitarios, públicos y/o privados, así como el que se realiza a cargo de empleadas /os de hogar".

- Cuidados mixtos: llevado a cabo entre el apoyo formal por su carácter remunerado e informal, lo conforman las y los empleadas y empleados de hogar, familia y el Estado (Minguela y Camacho, 2015; Aurtenetxe, 2007).

Saber cómo organizar socialmente los cuidados supone responder al menos a las siguientes cuestiones: ¿qué tipo de protección social?, ¿quién debe prestar los cuidados? y ¿cómo deben prestarse? Concretar este análisis supone revelar un sistema u otro de profesionalización de los cuidados. Es indudable que existen factores socioestructurales que limitarían las posibilidades de construcción de un empleo reconocido, cualificado y, por tanto, con buenas condiciones laborales. De este modo, uno de los problemas para organizar los cuidados de larga duración entraña construir un sistema de atención sociosanitaria con una estructura profesional clara (Recio, Borrás y Torns, 2015).

Existen al menos dos obstáculos para la profesionalización de los cuidados: en primer lugar, la dificultad de delimitar qué actividades se inscriben bajo el apéndice de “empleo de cuidados” (Christopherson, 
1997; Cameron y Moss, 2007; Anxo y Fagan, 2005). En segundo lugar, en el campo de la atención a las personas consideradas como dependientes, existe una categorización profesional con falta de requerimientos formativos, baja cualificación, bajos salarios, escaso reconocimiento profesional y pocas posibilidades de desarrollar una trayectoria profesional ascendente (Johansson y Moss, 2004 -citado en Recio, Moreno, Borràs y Torns, 2015-).

Por otra parte, si los trabajos domésticos y de cuidados no mercantiles han sido ignorados por la economía y los poderes públicos, no es de extrañar que al ser mercantilizados se hayan convertido en empleos de segunda y se desarrollen, muy a menudo, en condiciones de precariedad laboral. La crisis de cuidados y la incapacidad o la falta de disposición de pensar un cambio del modelo de trabajo han llevado a la denominada "crisis de los cuidados". Como explica Orozco, esta crisis ha sido resuelta (en los países capitalistas) por "las clases medias y altas de manera individual contratando (generalmente) a mujeres pobres de países más pobres" (Orozco, 2013). Así, en los países del sur de Europa, dadas las limitaciones de los Estados de Bienestar, la provisión de cuidados a las personas mayores dependientes por parte de las mujeres migrantes se está convirtiéndose en una de las fórmulas más habituales para dar respuesta a las necesidades que plantean los nuevos escenarios sociodemográficos (Nogueira y Zalakain, 2015; Federicci, 2013).

Los estudios con enfoque de género tienden a estudiar sobre todo las desigualdades entre mujeres y hombres. Sin embargo, desde la economía feminista se remarca la pertinencia de un análisis interseccional. La interseccionalidad constituye una herramienta analítica para la justicia de género y la justicia económica, ya que "sirve para estudiar, entender y responder a las maneras en que el género se cruza con otras identidades y cómo estos cruces contribuyen a experiencias únicas de opresión y privilegio" (AWID, 2004).

Es por ello por lo que nos gustaría señalar cómo las mujeres inmigrantes trabajadoras de hogar sufren una triple discriminación (Figura 1): las desigualdades producidas por razón de género, siendo mujeres se encuentran "condicionadas por sesgos de género, estructuras patriarcales y un entorno social y político opresor"; una discriminación por el origen -con consecuencias de disminución de derechos sociales, políticos y económicos por su condición de extrajeras-, y una discriminación por la clase social-como trabajadoras domésticas que tienen condiciones laborales deficientes y escaso acceso a sistemas de inspección, puesto que el trabajo se desarrolla en el hogar familiar- (Paulou, 2011; Nogueira y Zalakain, 2015). De todas maneras, esta triple discriminación no debe entenderse como una simple suma de discriminaciones, sino que esta intersección entre desigualdades conlleva una nueva desigualdad, que podemos denominar desigualdad interseccional (Cruells, 2015).

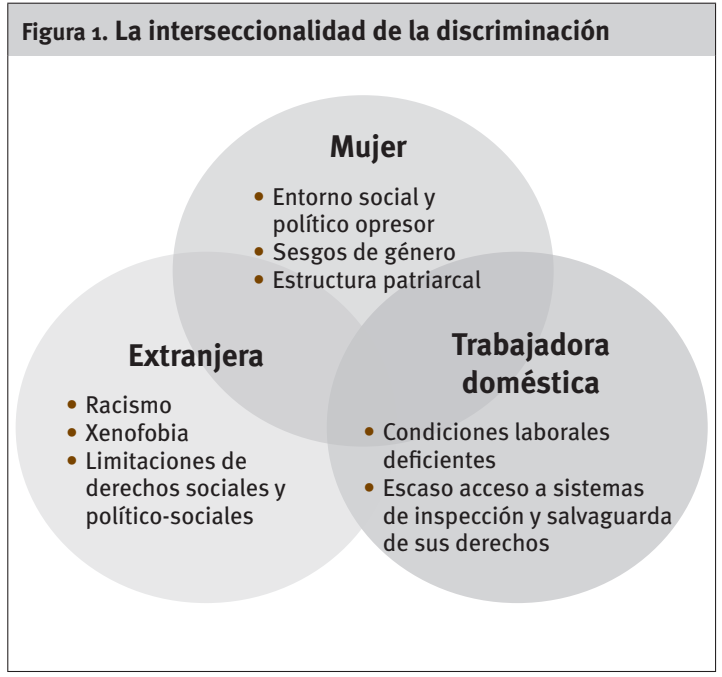

Fuente: Elaboración propia a partir de Paulou (2011).

\section{Marco jurídico del servicio de hogar familiar}

Las recomendaciones de la OIT recogidas en el convenio 189 fueron el punto de partida para la adecuación de la regulación en materia de empleo doméstico. Actualmente, en el Estado español la relación laboral en el sector del servicio doméstico se regula por tres normas: la Ley $27 / 2011$, de 1 de agosto, sobre actualización, adecuación y modernización del sistema de Seguridad Social (normaliza el ámbito de la Seguridad Social); el Real Decreto 1620/2011, de 17 de noviembre, de reforma del régimen laboral del empleo doméstico (regula la relación laboral de carácter especial del servicio de hogar familiar); y el Real Decreto 29/2012, de 28 de diciembre, de mejora de gestión y protección social en el Sistema Especial para Empleadas de Hogar y otras medidas de carácter económico y social.

Esta normativa ha supuesto un hito importante en la normalización del sector en los últimos años que ha derivado en la inclusión de estos trabajos en el Régimen General de la Seguridad Social y, por tanto, se les han reconocido ciertos derechos como el establecimiento de un salario mínimo, del tiempo de presencia y del descanso semanal, las bajas por maternidad, enfermedad o por accidente, la jubilación. Con la inclusión en el Régimen General de la Seguridad Social se visibiliza el empleo doméstico y se lo sustrae del ámbito privado e informal.

Ahora bien, estas normativas son deficientes en la medida en que se propuso la equiparación del Régimen General de la Seguridad Social de manera paulatina, cuando los movimientos sociales pedían una aplicación inmediata y total. Otra de sus deficiencias se refiere a que la prestación por desempleo queda fuera de la reforma, que las "horas de presencia" en las que el trabajador/a está a disposición del empleador/a sin realizar trabajo efectivo quedan abiertas a negociación 
entre las partes, cuando es obvio que la relación contractual entre empleadores/as y empleado/a es estructuralmente desigual. Además, estas normativas excluyen a los y las trabajadoras en situación administrativa irregular, cuestión de especial relevancia si tenemos en cuenta que un importante porcentaje de las trabajadoras del hogar que prestan servicios de cuidados son extranjeras y en situación administrativa irregular.

En las tablas 1 y 2 recogemos las principales características de las normas y una comparativa con la última actualización:

Tabla 1. Principales características del Real Decreto $1620 / 2011$

\begin{tabular}{|l|l|}
\hline Contrato & Obligatorio, por escrito \\
\hline $\begin{array}{l}\text { Período de } \\
\text { prueba }\end{array}$ & 2 meses. \\
\hline $\begin{array}{l}\text { Nómina o } \\
\text { recibo }\end{array}$ & Por escrito. \\
\hline Retribución & SMI* en cómputo anual (14 pagas). \\
\hline $\begin{array}{l}\text { Salario en } \\
\text { especie }\end{array}$ & $\begin{array}{l}\text { Descuento de hasta un 30\%. Se garantiza el SMI } \\
\text { en mano. }\end{array}$ \\
\hline $\begin{array}{l}\text { Tiempo de } \\
\text { Presencia }\end{array}$ & $\begin{array}{l}\text { Máximo de 20 horas por semana. Se deben } \\
\text { retribuir como horas de trabajo. Abierto a } \\
\text { negociación de las partes. }\end{array}$ \\
\hline $\begin{array}{l}\text { Descanso } \\
\text { Semanal }\end{array}$ & Derecho a 36 horas consecutivas. \\
\hline Despido & $\begin{array}{l}\text { Indemnización de } 20 \text { días por año trabajado, con } \\
\text { límite de 12 mensualidades. }\end{array}$ \\
\hline Desistimiento & $\begin{array}{l}\text { Notificación escrita e indemnización de 12 días } \\
\text { por año, con límite de 6 mensualidades. }\end{array}$ \\
\hline
\end{tabular}

*SMI: Salario Mínimo Interprofesional.

Fuente: Larenas et al., 2011:136

Tabla 2. Principales características de la Ley $27 / 2011$ y comparativa con el Real Decreto 29/2012

\begin{tabular}{|c|c|c|}
\hline & Ley $27 / 2011$ & Real Decreto 29/2012 \\
\hline $\begin{array}{l}\text { Alta en la } \\
\text { Seguridad } \\
\text { Social }\end{array}$ & $\begin{array}{l}\text { Derecho a cotizar } \\
\text { desde la primera hora. } \\
\text { El empleador debe } \\
\text { realizar el alta. }\end{array}$ & $\begin{array}{l}\text { Si los servicios que presta } \\
\text { la trabajadora son }>60 \\
\text { horas, está obligada a } \\
\text { darse de alta y cotizar a la } \\
\text { Seguridad Social. }\end{array}$ \\
\hline Cotización & $\begin{array}{l}\text { Sistema de tramos de } \\
\text { cotización, en función } \\
\text { del salario. }\end{array}$ & $\begin{array}{l}\text { Obligación de la } \\
\text { trabajadora de abonar la } \\
\text { cuota entera el empleador } \\
\text { sólo está obligado a pagar } \\
\text { la cuota patronal. }\end{array}$ \\
\hline Desempleo & \multicolumn{2}{|c|}{ Queda fuera de esta reforma } \\
\hline $\begin{array}{l}\text { Baja por } \\
\text { accidente }\end{array}$ & $\begin{array}{l}\text { Se cobra el } 75 \% \text { de } \\
\text { la base diaria de } \\
\text { cotización en el mes } \\
\text { anterior a la baja. }\end{array}$ & \multirow{2}{*}{$\begin{array}{l}\text { La cotización por } \\
\text { accidentes de trabajo } \\
\text { y enfermedades } \\
\text { profesionales por parte de } \\
\text { los empleados de hogar } \\
\text { se efectúa mediante los } \\
\text { tipos de cotización que } \\
\text { correspondan. }\end{array}$} \\
\hline $\begin{array}{l}\text { Baja por } \\
\text { enfermedad }\end{array}$ & $\begin{array}{l}\text { Se cobra un } 60 \% \\
\text { de la base diaria de } \\
\text { cotización del mes } \\
\text { anterior a la baja. Se } \\
\text { cobra a partir del día } 4 .\end{array}$ & \\
\hline $\begin{array}{l}\text { Baja por } \\
\text { maternidad }\end{array}$ & \multicolumn{2}{|c|}{$\begin{array}{l}\text { Durante las } 16 \text { semanas se cobra un subsidio del } \\
100 \% \text { de la base de cotización. }\end{array}$} \\
\hline Jubilación & $\begin{array}{l}\text { Tener } 65 \text { años y haber } \\
\text { cotizado } 15 \text { años. }\end{array}$ & $\begin{array}{l}\text { Deja de aplicarse lo } \\
\text { establecido en materia } \\
\text { de jubilación anticipada y } \\
\text { parcial. }\end{array}$ \\
\hline
\end{tabular}

Fuente: Elaboración propia a partir de la tabla recogida en Larenas et al., 2011:136; Roco (2015, octubre) y el Real Decreto 29/2012.
4. Prestaciones del Sistema para la Autonomía y la Atención a la Dependencia (SAAD): principales tendencias

La Ley de Promoción de la Autonomía Personal y Atención a las Personas en Situación de Dependencia entró en vigor en el año 2006 y supuso un progreso importante en el sistema de protección social y en la concepción de los derechos sociales de la ciudadanía, ya que reconoce como derecho subjetivo y universal el acceso a la cartera de servicios y prestaciones para personas en situación de dependencia. Mediante la citada ley se regulan las condiciones básicas para asegurar la igualdad en la atención a las personas dependientes y se establecen las bases para la creación del nuevo Sistema para la Autonomía y Atención a la Dependencia (SAAD), un sistema de protección específico y autónomo del sistema de Seguridad Social (Durán, 2015).

A nivel autonómico, la Ley 12/2008 de Servicios Sociales regula las condiciones básicas para garantizar el derecho a las prestaciones y servicios sociales en el ámbito de la Comunidad Autónoma de Euskadi, mediante la ordenación de un Sistema Vasco de Servicios Sociales de carácter universal. En la misma línea, el Decreto 24/2017 regula que el acceso a los servicios y prestaciones económicas del SAAD se hará a través de los servicios y prestaciones económicas del citado Sistema Vasco de Servicios Sociales.

EI SAAD ha tenido un escaso desarrollo por parte del Gobierno español y son las propias Administraciones autonómicas las encargadas del desarrollo efectivo del sistema de prestaciones. Las prestaciones económicas del SAAD son de tres tipos: Prestación Económica para Cuidados en el Entorno Familiar y Apoyo a Personas Cuidadoras No Profesionales (PECEF); Prestación Económica de Asistencia Personal (PEAP); y Prestación Económica Vinculada al Servicio (PEVS). En Gipuzkoa, las prestaciones del SAAD se hacen efectivas a través del Sistema Vasco de Servicios Sociales recogidas en primera instancia en el Decreto $185 / 2015^{3}$ y posteriormente en el Decreto $24 / 2017$.

En un inicio, la Ley de Dependencia planteaba la Prestación Económica para Cuidados en el Entorno Familiar y Apoyo a Personas Cuidadoras No Profesionales (PECEF) de manera excepcional, otorgándole un peso residual frente al resto de prestaciones. No obstante, en los primeros años de implantación del SAAD, la tendencia imperante en todo el Estado ha llevado a la PECEF a extenderse con relación a las otras prestaciones y servicios, convirtiéndose en protagonista del sistema al ocupar el primer puesto por número de asignaciones del catálogo de servicios y prestaciones. Este hecho genera una alteración en el funcionamiento originario

${ }^{3}$ Las dos principales prestaciones - la PECEF y la PEAP- son de competencia foral. 
del SAAD, ya que se está produciendo una sustitución de servicios profesionalizados por cuidados no profesionalizados.

A nivel del Estado, es en Gipuzkoa donde más se ha desarrollado la Prestación Económica de Asistencia Personal (PEAP). Así, el $84 \%$ de todas las asignaciones de esta prestación corresponden a Gipuzkoa. Por lo tanto, la figura de asistente personal, aun formando parte del catálogo de prestaciones, es una prestación económica de uso muy minoritario en el Estado español (Ortega, 2015).

Según los datos de Behagi, Observatorio Social de Gipuzkoa, a 31 de diciembre de 2017, la PECEF es la prestación más importante en cuanto al número de personas perceptoras, que asciende a 7.639 (58,66\%). Gracias a la Tabla 3, también apreciamos el constante incremento del número de perceptoras de la PEAP, que llega en dicho año a 5.167 personas (39,68\%), mientras que el número de personas que reciben la PEVS es de $217(1,67 \%)$, por lo que se mantiene prácticamente constante en los diez años estudiados.

Por su parte, el amplio desarrollo de la PEAP -evolución que se puede observar en el gráfico 1- en los últimos años en Gipuzkoa muestra la apuesta de la Diputación Foral de Gipuzkoa (DFG) por cambiar de dirección en el rumbo imperante hasta el momento, a favor del modelo originario planteado en la Ley de Dependencia basado en prestaciones de servicios y cuidados profesionales.

Tabla 3. Número de personas perceptoras de las diferentes prestaciones económicas en Gipuzkoa

\begin{tabular}{|l|c|c|c|c|c|c|c|c|c|c|}
\cline { 2 - 10 } \multicolumn{1}{c|}{} & $\mathbf{2 0 0 8}$ & $\mathbf{2 0 0 9}$ & $\mathbf{2 0 1 0}$ & $\mathbf{2 0 1 1}$ & $\mathbf{2 0 1 2}$ & $\mathbf{2 0 1 3}$ & $\mathbf{2 0 1 4}$ & $\mathbf{2 0 1 5}$ & $\mathbf{2 0 1 6}$ & $\mathbf{2 0 1 7}$ \\
\hline Cobertura PECEF (\%) & 2,46 & 4,44 & 5,75 & 5,02 & 5,33 & 4,85 & 4,48 & 5,03 & 5,16 & 4,91 \\
\hline Cobertura PEAP (\%) & 0,42 & 0,6 & 0,73 & 0,74 & 0,8 & 1,23 & 1,58 & 2,03 & 3,03 & 3,32 \\
\hline Cobertura PEVS (\%) & 0,08 & 0,1 & 0,11 & 0,11 & 0,1 & 0,08 & 0,11 & 0,08 & 0,11 & 0,14 \\
\hline $\begin{array}{l}\text { N. de personas } \\
\text { perceptoras de la PECEF }\end{array}$ & 3.170 & 5.839 & 7.930 & 6.743 & 7.504 & 6.977 & 6.617 & 7.573 & 7.887 & 7.639 \\
\hline $\begin{array}{l}\text { N. de personas } \\
\text { perceptoras de la PEAP }\end{array}$ & 542 & 786 & 1.005 & 990 & 1.130 & 1.771 & 2.337 & 3.064 & 4.640 & 5.167 \\
\hline $\begin{array}{l}\text { N. de personas } \\
\text { perceptoras de la PEVS }\end{array}$ & 98 & 138 & 144 & 149 & 138 & 108 & 162 & 114 & 173 & 217 \\
\hline $\begin{array}{l}\text { Total n. de personas } \\
\text { perceptoras de ayudas }\end{array}$ & $\mathbf{3 . 8 1 0}$ & $\mathbf{6 . 7 6 3}$ & $\mathbf{9 . 0 7 9}$ & 7.882 & $\mathbf{8 . 7 7 2}$ & $\mathbf{8 . 8 5 6}$ & $\mathbf{9 . 1 1 6}$ & $\mathbf{1 0 . 7 5 1}$ & $\mathbf{1 2 . 7 0 0}$ & $\mathbf{1 3 . 0 2 3}$ \\
\hline $\begin{array}{l}\text { Prestaciones PECEF sobre } \\
\text { el total (\%) }\end{array}$ & $83,20 \%$ & $86,34 \%$ & $87,34 \%$ & $85,55 \%$ & $85,54 \%$ & $78,78 \%$ & $72,59 \%$ & $70,44 \%$ & $62,10 \%$ & $58,66 \%$ \\
\hline $\begin{array}{l}\text { Prestaciones PEAP sobre } \\
\text { el total (\%) }\end{array}$ & $14,23 \%$ & $11,62 \%$ & $11,07 \%$ & $12,56 \%$ & $12,88 \%$ & $20,00 \%$ & $25,64 \%$ & $28,50 \%$ & $36,54 \%$ & $39,68 \%$ \\
\hline $\begin{array}{l}\text { Prestaciones PEVS sobre } \\
\text { el total (\%) }\end{array}$ & $2,57 \%$ & $2,04 \%$ & $1,59 \%$ & $1,89 \%$ & $1,57 \%$ & $1,22 \%$ & $1,78 \%$ & $1,06 \%$ & $1,36 \%$ & $1,67 \%$ \\
\hline $\begin{array}{l}\text { N. de personas de 65y } \\
\text { más años }\end{array}$ & 128.911 & 131.611 & 134.320 & 137.865 & 140.874 & 143.872 & 147.570 & 150.591 & 152.929 & 155.453 \\
\hline
\end{tabular}

Fuente: Elaboración propia a partir de datos de Behagi, Observatorio Social de Gipuzkoa, 2017.

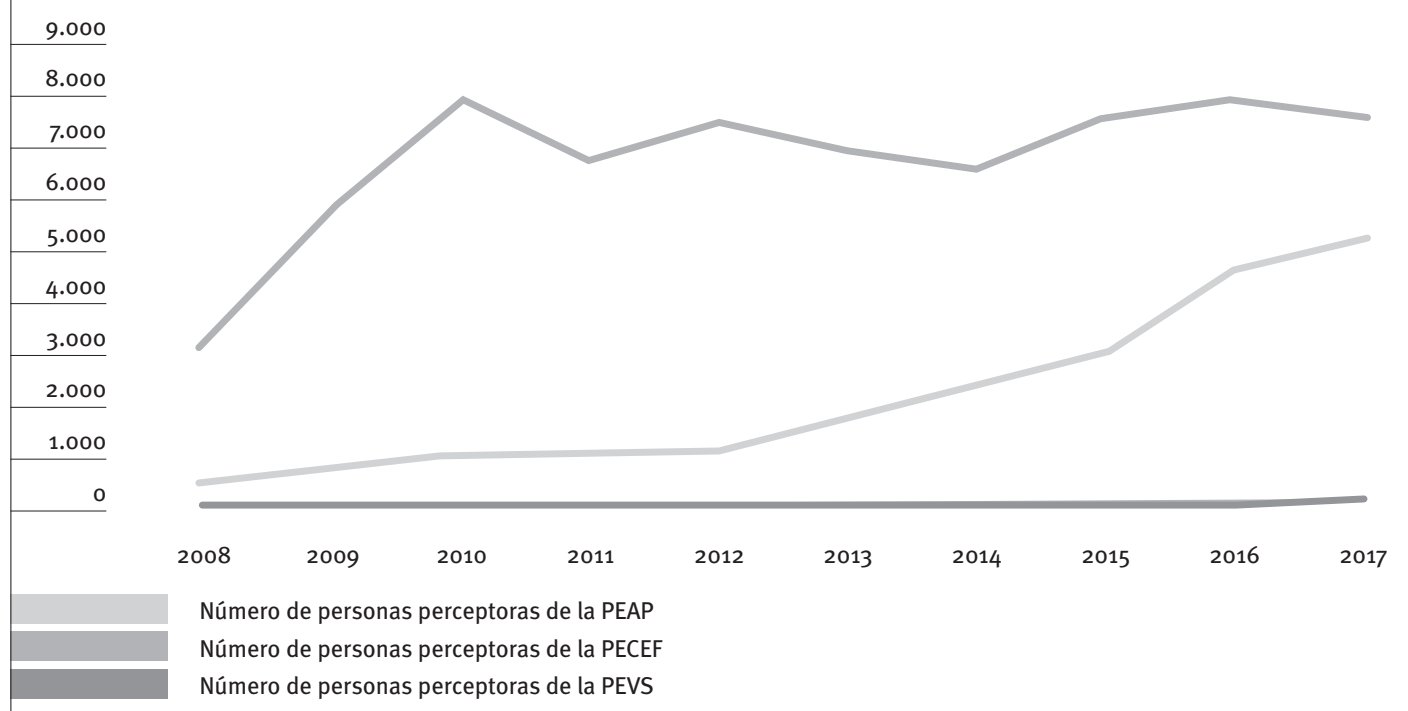

Fuente: Elaboración propia a partir de datos de Behagi. 
Tabla 4. Alcance de la PEAP, las personas beneficiarias, contratación y los/las asistentes personales contratados a través de la prestación

\begin{tabular}{|c|c|c|c|c|c|}
\hline & & \multicolumn{2}{|c|}{2013} & \multicolumn{2}{|c|}{2017} \\
\hline & & Absolutos & $\%$ & Absolutos & $\%$ \\
\hline \multicolumn{6}{|l|}{ Personas beneficiarias } \\
\hline \multirow{2}{*}{ Sexo } & Mujer & 1.318 & $72,0 \%$ & 4.925 & $70,0 \%$ \\
\hline & Hombre & 514 & $28,0 \%$ & 2.110 & $30,0 \%$ \\
\hline \multirow{4}{*}{ Edad } & $0-17$ & 19 & $1,1 \%$ & 27 & $0,4 \%$ \\
\hline & $18-64$ & 100 & $5,4 \%$ & 401 & $5,7 \%$ \\
\hline & $65-79$ & 355 & $19,4 \%$ & 958 & $13,6 \%$ \\
\hline & $>=80$ & 1.358 & $74,1 \%$ & 5.649 & $80,3 \%$ \\
\hline \multicolumn{6}{|l|}{ Contratación } \\
\hline \multicolumn{2}{|l|}{ Número de empresas contratadas } & 30 & - & 50 & - \\
\hline \multicolumn{2}{|l|}{ Número de personas que contratan empresas } & 175 & $9,5 \%$ & 1.011 & $14,4 \%$ \\
\hline \multicolumn{2}{|l|}{ Personas que contratan directamente a un/a asistente personal } & 1.657 & $90,5 \%$ & 6.024 & $85,6 \%$ \\
\hline \multicolumn{6}{|l|}{ Asistentes personales } \\
\hline \multirow{2}{*}{ Sexo } & Mujer & 1.567 & $94,5 \%$ & 5.716 & $95,1 \%$ \\
\hline & Hombre & 90 & $5,5 \%$ & 292 & $4,9 \%$ \\
\hline \multirow{2}{*}{ Nacionalidad } & Española & 521 & $31,5 \%$ & 3.278 & $54,6 \%$ \\
\hline & Otra & 1.136 & $68,6 \%$ & 2.730 & $45,4 \%$ \\
\hline \multirow{4}{*}{ Edad } & $0-24$ & - & - & 127 & $2,1 \%$ \\
\hline & $25-44$ & - & - & 2.675 & $44,5 \%$ \\
\hline & $45-64$ & - & - & 3.081 & $51,2 \%$ \\
\hline & $65-84$ & - & - & 131 & $2,2 \%$ \\
\hline
\end{tabular}

Fuente: Elaboración propia a partir de los datos facilitados por la Sección de Prestaciones Económicas de la Diputación Foral de Gipuzkoa a 31 de diciembre de 2017 y datos obtenidos de Benedicto, 2013.

Según los datos de la Tabla 4, en 2017 las personas beneficiarias siguen siendo, en su amplia mayoría, mayores de 80 años (80\%) y mujeres (70\%). En cuanto a la contratación, el 85,6\% de las personas contratan directamente a un/a asistente personal, si bien parece que cada vez hay más personas que contratan con empresas.

En lo que a los y las asistentes personales se refiere, se afianza el perfil totalmente femenino, ya que en 2017 son mujeres el $95 \%$ de los y las asistentes personales. El $45 \%$ de asistentes no tiene nacionalidad española; un año antes este porcentaje era del $47 \%$. Si se confirmara esta tendencia, podría deberse a varias razones: la variación del flujo migratorio (personas que por la mala situación económica tras el impacto de la crisis han dejado de venir y otras que han vuelto a sus países de origen), un aumento de la economía sumergida animado por una legislación encorsetada, y el cambio en el mercado laboral han podido tener un efecto directo sobre dicho descenso de la población no nacional que presta servicios de asistencia personal.

La PEAP favorece la prestación de servicios profesionales y especializados a personas dependientes, generando empleo regularizado alrededor de la actividad de atención y cuidados profesionales. En esta línea, en virtud de la Resolución del 2 de diciembre de 2008 de la Secretaría de Estado de Política Social, Familias y Atención a la Dependencia y a la Discapacidad, se han puesto en marcha una serie de medidas para que todas las y los profesionales que trabajan en servicios o centros de servicios sociales tengan acreditada la profesionalidad, bien por haber cursado estudios o por experiencia laboral documentada. Esta obligación también afecta a las personas asistentes personales (Benedicto, 2013). En el caso de ser solicitante de esta prestación la o el asistente personal con el que se vaya a trabajar deberá entre otros requisitos acreditar "Título o certificado de profesionalidad que acredite la cualificación profesional de la asistente personal, o si no, justificante de tener la habilitación provisional o excepcional para ejercer como tal" (Diputación Foral de Gipuzkoa, sin fecha).

En esta misma línea, caben mencionar igualmente los cambios del Decreto Foral 24/2017, de 12 de diciembre, por el que se regulan las prestaciones económicas de la Ley 39/2006, de 14 de diciembre, de Promoción de la Autonomía Personal y Atención a las Personas en situación de dependencia, que a continuación se detallan referidos exclusivamente a la PEAP: 
1. Se regulan los requisitos de cualificación profesional de la persona que ejerza de asistente personal "Tener la cualificación profesional de Atención Sociosanitaria a Personas en el Domicilio establecida por el Real Decreto 295/2004, de 20 de febrero" 4 .

2. Será necesario realizar la preinscripción en la convocatoria del Gobierno Vasco para la acreditación de las competencias profesionales ${ }^{5}$ exigible desde la fecha de efectividad del mismo [...] hasta el 31 de diciembre de 2022, en base a lo regulado en el Acuerdo del 19 de octubre de 2017;

3. En caso de que el servicio de asistencia personal lo preste una entidad, deberá estar inscrita en el Registro Foral de Servicios Sociales.

\section{Bases para poner en marcha las acciones de economía social y solidaria en el ámbito de cuidados en Gipuzkoa}

\subsection{El proyecto desarrollado}

El objeto del proyecto de investigación "Cooperativas de cuidados: de la Prestación Económica de Asistencia Personal hacia la colectivización de las

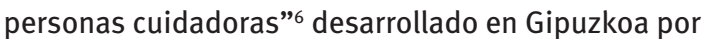
el Instituto GEZKI de la UPV/EHU fue identificar las necesidades del colectivo de cuidadoras de personas dependientes mayores que prestan su labor en el ámbito del hogar familiar, con el fin de determinar la idoneidad de promover su colectivización. La propuesta que planteamos es la colectivización de los cuidados a través de cooperativas de trabajo asociado, ya que a nuestro juicio dicha fórmula empodera a las trabajadoras -el poder está en manos de las personas trabajadoras "una persona un voto"-, y promueve la colaboración frente a la competencia.

Esta investigación siguió las guías del estudio Los cuidados informales en la Comunidad Autónoma de Euskadi, realizado por el Departamento de Vivienda y Asuntos Sociales del Gobierno Vasco (Leonardo, 2007), promovido por la Dirección de Bienestar Social

4 Se consideran los siguientes títulos: Técnico/a Superior en Integración Social, Técnico/a en Cuidados Auxiliares de Enfermería, Técnico/a de Atención a Personas en Situación de Dependencia, Certificado de Profesionalidad de Atención Sociosanitaria a Personas Dependientes en Instituciones Sociales, Certificado de Profesionalidad de Atención Sociosanitaria a Personas Dependientes en Domicilio y cualquier otro título o certificado que se publique con los mismos efectos profesionales.

${ }^{5}$ Se recogen en la Disposición Transitoria Primera, "La cualificación profesional de las y los asistentes personales regulada en el artículo11.3 f) del presente decreto foral, de Modificación del Acuerdo del Consejo Territorial de Servicios Sociales y del Sistema para la Autonomía y Atención a la Dependencia del 27 de noviembre de 2008.

${ }^{6}$ En el marco del proyecto "Gipuzkoako zaintza esparruan Ekonomia Sozial eta Solidarioko ekimenak martxan jartzeko oinarriak" financiada por el Departamento de Política Social de la Diputación Foral de Gipuzkoa. Nuestro interés se centra en presentar los resultados que obtuvimos en la primera línea de análisis donde trabajamos en el análisis de las necesidades de las cuidadoras y las posibilidades de colectivización. y cuyo objetivo era visibilizar el alcance del cuidado informal.

Se llevaron a cabo tres talleres de trabajo con catorce personas:

- En la primera sesión de trabajo, se realizaron tres grupos de discusión para detectar las necesidades de las cuidadoras.

- En segunda sesión de trabajo, se impartió un taller de formación: "Trabajo de Hogar: derechos y oportunidades" 7 .

- En la tercera sesión, se debatió en torno a las "posibilidades de colectivización" profundizando en la percepción de las trabajadoras en torno a las ventajas y los inconvenientes de emprender. Se buscó complementar la investigación mediante la acción participativa ${ }^{8}$.

El sector de los cuidados se caracteriza por ser un sector informal que no posee datos regionales fiables del colectivo objeto de estudio, por lo que se recurrido a la técnica de muestreo de bola de nieve que resulta particularmente útil para el estudio de poblaciones de difícil acceso (Corbetta, 2009). Este método se denomina así por tener un carácter acumulativo y la muestra9 se obtiene gracias a la red de contactos de las personas cuidadoras. Esta selección se llevó a cabo a través de dos canales: los contactos personales de las investigadoras y el servicio de inserción laboral de Cruz Roja. Se seleccionó a las personas ${ }^{10}$ que a juicio del equipo serían más idóneas para participar en el proceso participativo que se propuso. El perfil resultante fue: mujer (93\%), mayoritariamente extranjera (86\%), con una edad entre 22 y 61 años $(88 \%)$, con experiencia laboral de más de dos años, en su mayoría sin contrato de trabajo, y con personas a su cargo (71\%).

Con objeto de identificar las necesidades del colectivo de cuidadoras, en la primera sesión se

${ }^{7}$ Llevado a cabo por una experta en cuidados, Josefina Roco Sanfilipo.

${ }^{8}$ El sujeto en esta investigación han sido el grupo de investigación y la población, la finalidad ha sido la de concienciar y hacer un análisis de la realidad por la acción y dinamización, activando la imaginación colectiva para intentar conseguir una mejor calidad de vida para las cuidadoras.

9 Así también, los criterios de inclusión son los que siguen: la muestra se ha seleccionado a través de un rango de edad de 18 a 65 años de edad, cuya actividad laboral sea la del cuidado de personas mayores dependientes en el hogar familiar - con o sin contrato laboral-, con uno o varios empleadores, con o sin formación específica en cuidados y, finalmente, tanto en régimen de externa como de interna, considerando la experiencia laboral como cuidadora, pero sin considerar el grado de dependencia de la persona a la que cuidan o han cuidado. Además, se ha de resaltar que esta población de estudio no se encuentra registrada en ningún censo por lo que el muestreo por bola de nieve ha sido un recurso muy práctico.

${ }^{10}$ Los criterios que se utilizaron para la clasificación de los grupos fueron: Grupo 1, cuidadoras con formación específica en el ámbito de los cuidados, con estudios superiores y con experiencia en el cuidado; Grupo 2, cuidadoras con alguna formación en el ámbito de los cuidados, estudios primarios y con experiencia en el cuidado; Grupo 3, personas sin formación específica en el ámbito de los cuidados, con estudios medios o técnicos y con experiencia laboral en cuidados. 
utilizó una batería de preguntas semidirigidas que se organizó en cinco bloques de cuestiones basándonos en la investigación de Aurtenetxe (2014): 1. Consecuencias del cuidado dispensado sobre las personas cuidadoras (consecuencias ocio y vida familiar, consecuencias salud y estado general y consecuencias profesionales-económicas); 2. Necesidad de ayuda auxiliar; 3. Necesidades formativas para el cuidado (tipo de formación y quién imparte la formación); 4. Canales habituales de orientación; 5. Expectativas sobre los cuidados futuros.

Para debatir sobre las potencialidades y dificultades que se les podrían presentar a las trabajadoras de hogar a la hora de poner en marcha una iniciativa de emprendimiento colectivo, en la tercera sesión, como ya hemos mencionado, se llevaron a cabo unas dinámicas de grupo, en las que se trabajaron como principales variables los intereses y ventajas de una iniciativa de emprendimiento en colectivo, los límites y dificultades que pudieran surgir de dicha iniciativa y también las posibles soluciones para solventar las dificultades (Figura 3).

\subsection{Resultados del proyecto}

Hemos ordenado los resultados del diagnóstico de las necesidades de las cuidadoras en base a seis ítems que resumimos a continuación, y cuyas ideas más destacadas sintetizamos en la Figura 2.

A. Percepción de las cuidadoras sobre el empleo DE HOGAR: las cuidadoras externas perciben que las jornadas laborales son largas, los horarios poco flexibles -incluso rígidos, restrictivos y agobiantes-, la carga de trabajo elevada y en solitario, tienen dificultad para ser sustituidas en caso de necesidad (como por ejemplo para acudir a una cita médica), poco poder de negociación frente al empleador (atribuido a la gran oferta de cuidadoras) y resaltan que se genera apego emocional hacia la persona cuidada. Del relato de las internas, destacamos su falta de intimidad, falta de libertad de decisión, los horarios rígidos, la dificultad para conciliar los tiempos para dedicar a la familia y al trabajo, los bajos salarios, la dependencia del trabajo, el aislamiento y la falta de redes de apoyo. En el caso de cuidadoras con personas a cargo, perciben que tienen una gran responsabilidad -doble dependencia a su cargo-, gran dificultad para conciliar la vida familiar y laboral, dificultad para hacer frente a los costes de pagar a otra cuidadora para cuidar a la persona que tienen a cargo. Una característica común entre ellas es que los familiares que residen en los países de origen han establecido una dependencia económica.

B. Consecuencias del trabajo dispensado en SU SALUD Y ESTADO EN GENERAL: revelaron sentimientos de aislamiento y soledad, de agobio, cambios anímicos y mal humor. Además, las cuidadoras extranjeras manifestaron no tener derecho a la asistencia sanitaria, sin residencia o contrato laboral. Las consecuencias sobre sus cuerpos son dolores de espalda, de cabeza, dolor en muñecas, estrés y ansiedad. El esfuerzo físico depende de las características físicas de la persona dependiente y los problemas de salud están estrechamente relacionados con el grado de dependencia que tenga la persona cuidada. Señalan tener dificultad para que otra persona las sustituya y poder acudir al médico; exteriorizan sentir que no se pueden expresar, falta de privacidad.

C. Consecuencias derivadas de las condiciones DE TRABAJO ${ }^{11}$ : manifiestan percepción de vulnerabilidad -mayor en las cuidadoras sin permiso de trabajo-, falta de disponibilidad frente a situaciones imprevistas, disponibilidad para adecuarse a los horarios de los familiares, gasto en desplazamiento para horas que finalmente no son cubiertas y que no se contemplan en el salario y, finalmente, horas de trabajo extra no pagadas. Reconocen sentirse infravaloradas por no tener derecho a desempleo como trabajadoras de hogar y esto hace que su situación sea de completa incertidumbre en caso de que fallezca la persona cuidada. Remarcaron asimismo que sus tareas van más allá de lo que concierne a la persona dependiente, pues deben ocuparse de tareas del hogar e incluso de otros familiares y del empleo de hogar como recoge su definición.

D. CONSECUENCIAS EN EL OCIO Y EN LA VIDA FAMILIAR: destacamos la desatención a su familia, lo que hace que tengan que dejar a cargo de otras personas a sus propios familiares dependientes, el hecho de dejar de lado la vida privada, la falta de tiempo libre, la difícil conciliación entre la vida laboral y familiar, dificultad que se acrecienta cuando tienen más de un empleador.

E. NECESIDADES DE LAS CUIDADORAS, NECESIDADES PARA EL CUIDADO DE LAS PERSONAS DEPENDIENTES Y CANALES DE INFORMACIÓN.

- Necesidades propias son: tiempos para la conciliación, guarderías a precios asequibles para ellas, vivienda, asistencia sanitaria, tiempos de descanso, de útiles o herramientas como fajas, guantes (esta necesidad también se puede clasificar dentro de las necesidades para el cuidado de la persona dependiente) y necesidad de espacios urbanos más adaptados, además de la necesidad de mejorar los salarios.

- Entre las necesidades para el cuidado de las personas dependientes destacan: formación específica de cuidados, herramientas

${ }^{11}$ Conviene subrayar cuáles son las condiciones de trabajo de las trabajadoras de hogar: el acuerdo previo entre empleador y empleada varía, sueldos bajos, días festivos no pagados, obligación de preaviso que solo cumplen las cuidadoras, perder otras oportunidades de empleo debido al apego a la persona que cuidan, imposibilidad para renovar el permiso de trabajo sin contrato de trabajo, falta de poder de negociación, estar condicionadas a la voluntad del empleador. 
(guantes, sillas de ruedas, muletas, etc.), hogares mejor adaptados, en algunos casos conocimiento del euskera y otras necesidades dependiendo de las demandas del empleador (carnet de conducir, carnet de manipulador de alimentos, certificación sociosanitaria como cuidadora).

- En cuanto a las necesidades formativas e informativas, estas también se ven condicionadas por el grado de dependencia de la persona y sus características físicas. La formación, en cualquier caso, debería recoger: tiempo de adecuación al empleo, información sobre las labores a desempeñar, preparación psicológica para saber gestionar los sentimientos, para afrontar posibles conflictos con la familia, formación en empatía, paciencia, preparación específica para cuidar personas con alzheimer, formación en técnicas para mover a personas con movilidad reducida, para saber cuidar "en la medida" de lo que necesiten, para conocer los recursos de los que pueden disponer las personas dependientes. Demandan tener acceso a la formación y el reconocimiento de derechos aun sin permiso de residencia y de trabajo.

- Por último, los canales habituales de información son las redes de contactos y algunas entidades de la economía social y solidaria y para la orientación en la búsqueda de empleo se valen principalmente del boca a boca (por recomendación), de empresas de trabajo temporal (algunas especializadas en el servicio domiciliario) y de espacios informales de orientación.
F. EXPECTATIVAS SOBRE EL FUTURO: diferenciadas entre las expectativas sobre su situación y expectativas personales.

- En el primer caso, desearían superar la incertidumbre, conseguir una mejora de las condiciones laborales y poder contar con la existencia de un "ente" intermediario, es decir, de una institución de apoyo o una empresa que medie entre las partes.

- En el segundo caso, desearían tener la posibilidad de dedicar tiempo a la formación en diferentes ámbitos y encontrar otro empleo con mejores condiciones laborales.

Como ya hemos mencionado, se realizó un tercer taller que tenía como eje central trabajar la posibilidad de colectivización de las cuidadoras mediante la fórmula cooperativa. En este taller y en relación con la estrategia de colectivización:

- Las ventajas que señalan son: la estabilidad y seguridad laboral, poder estructurar de antemano las jornadas laborales y disponer de más tiempo para cuidar a sus familiares. Consideran que el emprendimiento colectivo les permitiría asimismo adecuar los turnos y ritmos de trabajo a las necesidades de cada una, mayor autonomía e independencia, oportunidad de participar en las decisiones de la empresa, tener igualdad de condiciones entre las socias, disponer de acceso a la formación, disponer de un soporte o red de apoyo, mayor valoración de su trabajo, motivación personal e ilusión y satisfacción de tener un proyecto propio de emprendimiento.

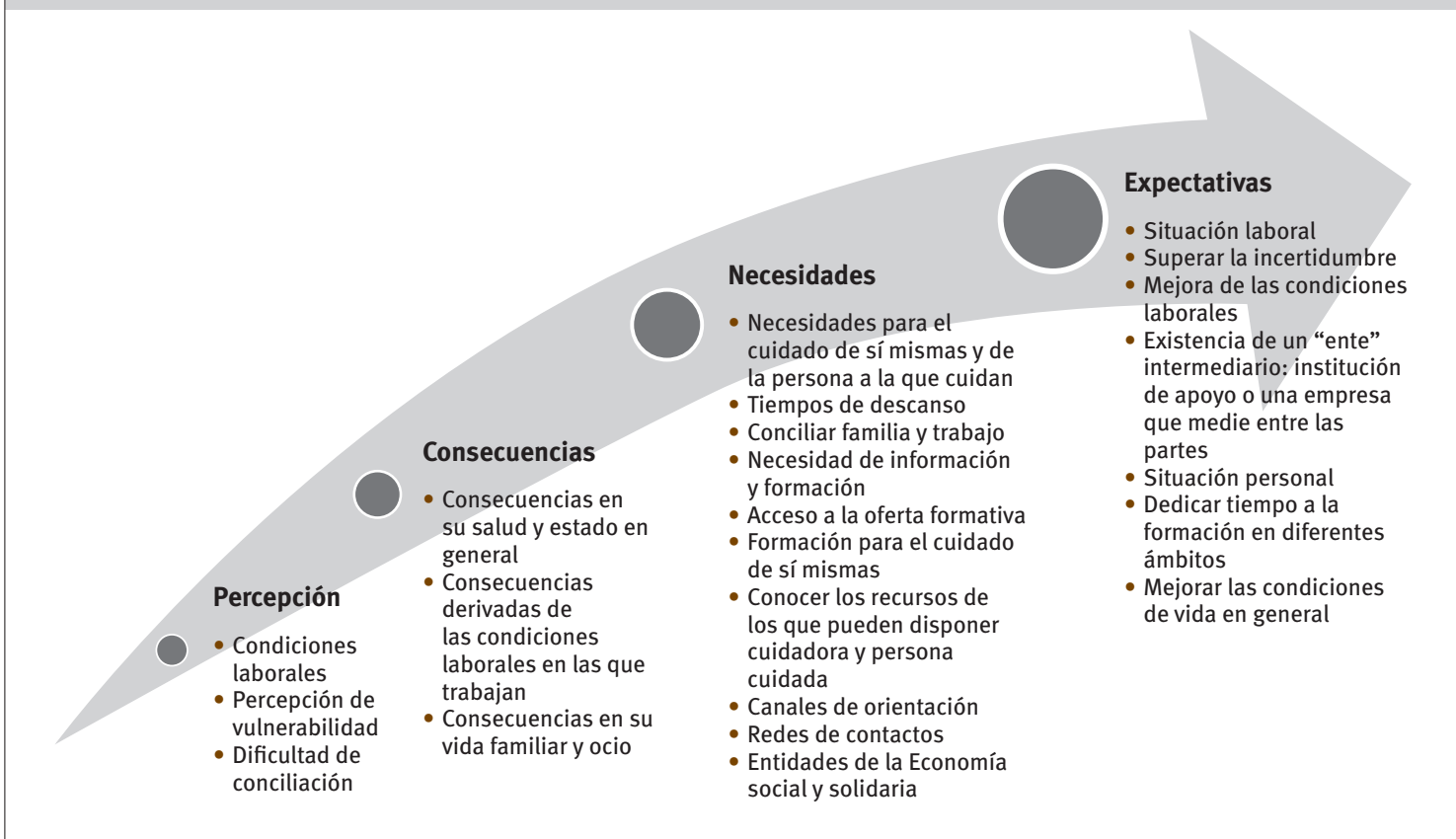

Fuente: Elaboración propia. 
- Entre los límites de la iniciativa que señalaron: la dificultad a la hora de proyectar y desarrollar los posibles límites e impedimentos. Los principales obstáculos son los relacionados con el aspecto económico del proyecto: la incapacidad para aportar el capital inicial, dificultad para conseguir un préstamo (tengamos en cuenta que algunas manifestaron problemas a la hora de abrir una cuenta corriente en un banco cualquiera). Además, conviene subrayar el miedo e inseguridad a enfrentarse a la tarea de la gestión de la empresa, por la que consideran necesaria la contratación de una gestoría o asesoría que les guiase a lo largo del proceso. Otro aspecto a reseñar es la percepción de un exceso de trámites y la falta de información. En cuanto al aspecto técnico del emprendimiento, subrayaron la necesidad de elaborar un plan de negocio y una estrategia de marketing para promocionar sus servicios, además de tener que superar estereotipos como el de "mujer migrante sin papeles, con un perfil de trabajadora de hogar flexible y mano de obra barata" con el que se las identifica. En cuanto a la gestión con personas, consideraron un obstáculo que pudiera surgir una falta de compromiso o la existencia de diferentes niveles de responsabilidad. Para terminar, señalaron posibles dificultades a la hora de gestionar el conflicto en la organización y también para separar, en su condición de socias, su vida personal y laboral.

- Las propuestas para superar las dificultades son: urgente necesidad de capacitarse, disponer de un espacio físico o virtual en el que formarse, adquirir habilidades que les permitan gestionar de manera adecuada, poder disponer de un proceso de aprendizaje especializado y adaptado, también disponer de un espacio físico donde poder gestionar la cooperativa (cedido por alguna entidad pública o privada), tener acceso a formas de financiación, disponer de ayudas económicas dirigidas a cooperativas.

En la Figura 3 sintetizamos las principales ventajas de la estrategia de colectivización, así como las dificultades percibidas y su apreciación de cómo superar dichas dificultades mencionadas.

\subsection{Discusión sobre la propuesta de colectivización de los cuidados a través de cooperativas de trabajo asociado}

La estrategia de formalizar el sector a través de emprendimientos colectivos posee una serie de virtudes que permitirían afrontar las características negativas del empleo de cuidados que se han subrayado en el diagnóstico que hemos presentado. En la Tabla 5 exponemos la relación entre los resultados del diagnóstico de las necesidades y las respuestas que se pueden dar desde la estrategia cooperativa. Apuesta por la estrategia cooperativa que nos ayuda a identificar de manera más clara cuáles son las situaciones que viven las cuidadoras y qué respuesta puede darse.

Esta propuesta de colectivización plantea una serie de interrogantes entre los que destacamos la financiación. Es decir, ¿cómo se financiaría tanto la creación de cooperativas de cuidados? Algunos estudios (Intersocial, 2017) ${ }^{12}$ afirman que existen motivos económicos para fomentar el uso de la

Figura 3. Principales ventajas, límites y formas de superar las dificultades de la estrategia de colectivización

- Estabilidad laboral

- Emprender en colectivo

- Acceso a la formación

- Disponer de red de

apoyo

- Conseguir que se valore

su trabajo

- Motivación personal
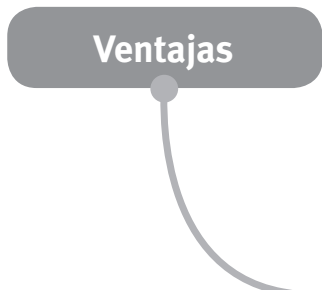

\section{Límites}

- Dificultad para proyectar los límites

- Obstáculos económicos

- Inseguridad en

la gestión de la

organización

- Necesidad de

externalizar ciertas

tareas

- Gestionar el conflicto

- Estereotipos
- Necesidad de

capacitarse

- Aprendizaje

especializado y

adaptado

- Cesión de espacio de

trabajo

- Acceso a financiación,

ayudas económicas a

cooperativas

- Superar estereotipos

Cómo superar

las dificultades

Fuente: Elaboración propia.

${ }^{12}$ Se trata de una investigación econométrica sobre asistencia personal y atención residencial encargada por la Oficina de Vida Independiente de la Comunidad de Madrid. 
Tabla 5. Relación entre el diagnóstico de las principales necesidades y la estrategia cooperativa

\begin{tabular}{|c|c|}
\hline Diagnóstico de la situación de las cuidadoras & Respuesta de la estrategia cooperativa \\
\hline $\begin{array}{l}\text { - Percepción de soledad } \\
\text { - Falta de redes de apoyo } \\
\text { - Carga de trabajo en solitario }\end{array}$ & Romper con la atomización y el aislamiento \\
\hline $\begin{array}{l}\text { - Falta de poder de negociación } \\
\text { - Horarios rígidos } \\
\text { - Bajos salarios }\end{array}$ & Mejora efectiva en las condiciones de trabajo \\
\hline $\begin{array}{l}\text { - Necesidad de accesorios para el desarrollo de su trabajo (fajas, } \\
\text { guantes...) }\end{array}$ & Capacidad de inversión para la adquisición de útiles o herramientas \\
\hline $\begin{array}{l}\text { - Necesidad de un tiempo para adaptarse al empleo } \\
\text { - Saber afrontar el conflicto con la familia } \\
\text { - Necesidad de tiempo para dedicar a la formación } \\
\text { - Formación para cuando la enfermedad es alzhéimer } \\
\text { - Conocer técnicas para mover a personas con movilidad reducida }\end{array}$ & $\begin{array}{c}\text { Contexto más favorable para la formación, capacitación y el reciclaje } \\
\text { profesional }\end{array}$ \\
\hline $\begin{array}{l}\text { - Necesidad de reconocimiento de la labor que desempeñan } \\
\text { - Necesidad de reconocimiento de los derechos a personas en } \\
\text { situación administrativa irregular }\end{array}$ & $\begin{array}{l}\text { Empoderamiento de personas en clara situación de vulnerabilidad } \\
\text { social y precarización laboral }\end{array}$ \\
\hline
\end{tabular}

Fuente: Elaboración propia.

PEAP que tiene como finalidad cubrir en parte los gastos para la contratación de un/una asistente personal. Ahora bien, la cuantía máxima de la PEAP no cubriría las necesidades de cobertura que pueda tener una persona con gran dependencia por lo que la administración pública debería tomar parte a través de las aportaciones al modelo cooperativo y garantizar así la provisión de un servicio social. Las cooperativas presentan además una estructura sumamente flexible, que admite diferentes combinaciones - cooperativa mixta, integral y de iniciativa social- lo que abre la puerta a diferentes grupos de interés o stakeholders.

Desde una perspectiva más global, consideramos que hay que establecer tres premisas a favor de un adecuado desarrollo del sector (Etxezarreta et al., 2015: 33). Por un lado, el reto fundamental de los servicios sociales sigue siendo aún invertir el peso de la informalidad, lo cual únicamente se puede alcanzar a través de una mayor participación pública. El reto de cooperativizar, por tanto, no iría en detrimento del sector público, no supondría una contracción del sector público, sino que acompañaría su extensión.

En segundo lugar, plantear una privatización al uso, apoyada en entidades privadas lucrativas, genera una serie de riesgos para la Administración Pública, para las y los trabajadores del sector, para las propias personas usuarias, siendo el sector público en última instancia quien asume los costes de dichos riesgos. Estos riesgos se derivan de la propia lógica del sector capitalista privado, centrado en la búsqueda del beneficio, frente o en detrimento de un servicio de calidad. Creemos que el hecho de aceptar márgenes de beneficio para las empresas privadas en la provisión de una necesidad social financiada públicamente debería suscitarnos una profunda reflexión, aun cuando el margen de beneficio fuera el menor posible. Dejar los servicios públicos en manos de empresas con ánimo de lucro debería ser valorado como una práctica política de escasa responsabilidad social. Por todo ello, la cooperativización se plantea como alternativa a la privatización, ya que consideramos que una cogestión de los servicios públicos junto con las entidades de la economía social es la forma más garantista de afrontar un proceso de externalización.

Por último, otro de los vértices del debate, el del coste (laboral) del sistema, únicamente se puede resolver de una forma decente si se tiende a la dignificación general de las condiciones laborales del sector. Plantear una pugna entre personas trabajadoras en la esfera pública y aquellas que lo hacen en el ámbito privado es una estrategia de corto recorrido. En este sentido, las experiencias autogestionarias pueden dar pie a plantear convenios propios y políticas de retribución más favorables a las propias trabajadoras del sector.

Una de las formas de responder a estas tres cuestiones se podría articular desde lo público, con una idea de republificar aquello que ya se ha externalizado anteriormente. Consideramos que esta estrategia, aun siendo plenamente legítima, cuenta con una serie de obstáculos (tanto políticos como presupuestarios) que harían inviable su consecución efectiva. En este contexto, y con el fin último de responder de alguna manera al incremento de la demanda de servicios sociales, planteamos la validez de la alternativa mutualista o cooperativa. Consideramos, pues, que la alternativa mutualista muestra algunas ventajas tanto para la Administración Pública como para las propias personas trabajadoras y usuarias del sistema.

Desde el punto de vista de las instituciones públicas, la cooperativización del sistema ofrece una solución relativamente prudente a un gran dilema ético: el de dejar los servicios públicos en manos de empresas privadas. Las cooperativas son en algunos casos (cooperativas de iniciativa social) empresas no lucrativas y garantizan un tratamiento más comunitario de los beneficios. Establecen la condición de la imposibilidad de reparto de excedentes entre las personas socias (en el primer caso), o bien lo hacen de una forma mucho más transparente y auditable. 
Defendemos, pues, que la fórmula cooperativa puede ofrecer mayores garantías que las entidades lucrativas, pero también son más garantistas de cara a la Administración Pública que las propias entidades sin ánimo de lucro (asociaciones y fundaciones) en lo que al tratamiento comunitario de los beneficios se refiere.

Con vistas a evitar los fallos del mercado, las cooperativas presentan además una estructura sumamente flexible, que admite diferentes posibles combinaciones, lo que abre la puerta a diferentes stakeholders para el control del servicio. Por ejemplo, si el objetivo reside en la búsqueda de fórmulas para una mayor participación del sector público, se puede optar por conformar cooperativas mixtas, en las cuales las instituciones públicas participarían en el capital social como socios colaboradores. Esta participación en la entidad cooperativa dotaría al sector público de mayor capacidad de inspección en ella, a la vez que daría una mayor solvencia a la cooperativa para afrontar inversiones o proyectos de mayor alcance.

En cambio, si fuéramos más proclives a modelos más autónomos y mutualistas, se podrían plantear cooperativas integrales, donde el control lo ejercerían las personas trabajadoras junto con las usuarias, tal y como sucede en algunas cooperativas de enseñanza. Finalmente, cabría la opción de las cooperativas de iniciativa social, modelo poco explorado en nuestro entorno pero que cuenta con amplia trayectoria en diversas regiones de Italia y del que se podrían importar algunos aprendizajes interesantes.

Además, las cooperativas podrían tener otros efectos positivos de carácter general y que beneficiarían, por tanto, al conjunto de la sociedad. Entre ellos destacamos que repercutiría en una mejor distribución de la riqueza. En esta línea, la propuesta predistributiva aboga por medidas antes de distribución que generarían un efecto preventivo en la generación de desigualdades económicas. Según el Modelo Predistributivo, algunos tipos de organización de la actividad económica pueden generar más o menos desigualdad, es decir, hay organizaciones económicas que, ya sea por su estructura de la propiedad y/o de gobernanza, son más igualitarias que otras (Zalakain y Barragué, 2017).

Esta afirmación se respalda, según Hansmann (en Ferreti, 2017), en el hecho de que la estructura de propiedad de una organización tendrá efectos directos en la forma en que se distribuirán los ingresos, el capital y el poder dentro de ella. Podemos también ir más lejos y afirmar, como hace Ferreti (2017), que la estructura de propiedad, junto con la gobernanza de las organizaciones, contribuyen también a la mayor o menor generación de desigualdades en la propia sociedad, al ser las personas integrantes de las empresas agentes determinantes de la misma.

De entre los diferentes tipos de organizaciones, entendemos que la cooperativa de trabajo asociado es una de las que menor desigualdad genera, por varias razones que se interrelacionan. Por una parte, la gobernanza es democrática (una persona, un voto), lo cual significa que las decisiones más relevantes se toman en colectivo (mediante la asamblea general) y la disparidad del poder en el seno de la empresa es menor que en otros tipos de organizaciones. Por otra parte, la propiedad se encuentra distribuida entre las personas socias, lo cual repercute en unos niveles de desigualdad muy inferiores respecto a otras empresas en lo que a la distribución del capital (y poder) se refiere. Por último, al estar la propiedad repartida entre las personas socias, los beneficios se distribuyen entre ellas de manera más equitativa. También cabe destacar que, relacionado con el reparto de los beneficios, un porcentaje de está destinado a los fondos de reserva obligatorios y voluntarios, y no se puede distribuir entre las personas socias.

\section{Conclusiones}

La evolución demográfica reciente y la futura demanda de cuidados requieren un fuerte impulso al apoyo al cuidado de las personas dependientes y una apuesta por la profesionalización de estos cuidados. Por otro lado, la alternativa cooperativa puede hacer frente a precariedad laboral de las cuidadoras de personas dependientes. La cooperativización rompería también con la atomización y el aislamiento, crearía capacidad de inversión para la adquisición de útiles o herramientas, propiciaría un contexto más favorable para la formación, capacitación y el reciclaje profesional y, finalmente, impulsaría el empoderamiento de personas en clara situación de vulnerabilidad social. Además, un mayor peso económico de las cooperativas se traduciría en una serie de ventajas sociales y económicas entre las que destacamos una distribución más equitativa de la riqueza. Ahora bien, el impulso de las cooperativas de cuidados exige la implicación y la inversión de las Administraciones Públicas.

Hoy asistimos a un panorama donde los esfuerzos por dar apoyo a las personas cuidadoras se concentran en el autocuidado, no en vano venimos mencionando las características de un trabajo que además de ser duro está poco valorado. En este recorrido hemos aprendido que resulta fundamental dar un fuerte impulso al apoyo al cuidado de las personas dependientes y una apuesta igualmente por la profesionalización adaptada a las necesidades de las cuidadoras y que contemple todos los aspectos del cuidado como se evidencia en los reclamos de las cuidadoras. 
AWID (2004): “Interseccionalidad: Una herramienta para la justicia de género y la justicia económica", Derechos de las mujeres y cambio económico, no 9. Género y derechos, 〈https://www. awid.org/sites/default/files/atoms/files/ nterseccionalidad_-_una_herramienta_ para_la_justicia_de_genero_y_la_justicia_ economica.pdf〉.

BENEDICTO, Z. (2013): “La prestación económica de asistencia personal en el territorio histórico de Gipuzkoa”, Zerbitzuan, nํ5, 54 , págs. 6784, 〈https://www.siis.net/es/publicaciones/ zerbitzuan/〉, 〈https://doi.org/10.5569/11347147.54.04>.

CARRASCO, C. (2013): "El cuidado como eje vertebrador de una nueva economía", Cuaderno de Relaciones Laborales, vol. 31, no 1, págs. 39-56 <http:// revistas.ucm.es/index.php/CRLA/article/ view/41627/39688>.

CARRASQUER, P. (2013): “El redescubrimiento del trabajo de cuidados: algunas reflexiones desde la sociología", Cuadernos de Relaciones Laborales, vol. 31, no 1, págs. 91-113, 〈http:// revistas.ucm.es/index.php/CRLA/article/ viewFile/41633/39693>.

CORBETTA, P.; FRAILE, C.; y FRAILE, M. (2010): Metodología y técnicas de investigación social, Madrid, McGraw Hill.

CRUELLS, M (2015): “La interseccionalidad política: tipos y factores de entrada en la agenda política, jurídica y de los movimientos sociales", tesis doctoral, Barcelona, Institut de Govern i Politiques Públiques de la Universitat Autònoma de Barcelona <https://www.tdx.cat/ bitstream/handle/10803/288224/mclide1. pdf? sequence $=1$ \&isAllowed $=y$. .
DALY, M. y LEWIS, J. (2000): “The concept of social care and the analysis of contemporary welfare states", British Journal of Sociology, vol. 51, $\mathrm{n}-2$, págs. 281-298, «http://citeseerx.ist.psu.edu/ viewdoc/download?doi=10.1.1.530.3843\&rep=r ep1\&type $=p d f>$.

DIPUTACIÓN FORAL DE GIPUZKOA (2018): Aurrekontua Presupuestos 2018, 〈www4.gipuzkoa.net〉.

- (sin fecha): Prestación económica de asistencia personal -PEAP-, Información general, <https:// egoitza.gipuzkoa.eus/es/listado-tramites/-/ tramiteak/xehetasuna/849>.

DURÁN BERNARDINO, M. (2015): “El retroceso de la dependencia en pro de la estabilidad presupuestaria y el fomento de la competitividad", Zerbitzuan, $\mathrm{n} \div 58$, págs. 27-40, <https://www.siis.net/es/ publicaciones/zerbitzuan/〉. 〈https://doi. org/10.5569/1134-7147.58.03>.

ESPAÑA (2014): Ley 36/2014, de 26 de diciembre, de Presupuestos Generales del Estado para el año 2015, Boletín Oficial del Estado, n우 315, 30-12-14, págs. 106.153-106.659, 〈https:// www.boe.es/boe/dias/2014/12/30/pdfs/ BOE-A-2014-13612.pdf >.

- (2014): Real Decreto 1106/2014, de 26 de diciembre, por el que se fija el salario mínimo interprofesional para 2015, Boletín Oficial del Estado, ํㅜ 313, 27-12-14, págs. 105.840-105.842, «https:// www.boe.es/boe/dias/2014/12/27/pdfs/ BOE-A-2014-13518.pdf >.

- (2012): Real Decreto 29/2012, de 28 de diciembre, de mejora de gestión y protección social en el Sistema Especial para Empleados de Hogar y otras medidas de carácter económico y social, Boletín Oficial del Estado, nํ314, págs. 
89.536-89.557, <https://www.boe.es/boe/ dias/2012/12/31/pdfs/BOE-A-2012-15764.pdf .

- (2011): Real Decreto 1620/2011, de 14 de noviembre, por el que se regula la relación laboral de carácter especial del servicio del hogar familiar, Boletín Oficial del Estado, no 277, págs. 25.617-25.618 <https://www.boe.es/boe/dias/2011/11/17/ pdfs/BOE-A-2011-17975.pdf >.

- (2011): Ley 27/2011, de 1 de agosto, sobre actualización, adecuación y modernización del sistema de Seguridad Social, Boletín Oficial del Estado n- 184, disposición adicional 39 y disposición transitoria única, 〈https://www.boe.es/boe/ dias/2011/08/02/pdfs/BOE-A-2011-13242.pdf〉.

- (2006): Ley 39/2006, de 14 de diciembre, de Promoción de la Autonomía Personal y Atención a las Personas en Situación de Dependencia, Boletín Oficial del Estado, no 299, págs. 44.142-44.156 <https://www.boe.es/buscar/pdf/2006/BOE-A2006-21990-consolidado.pdf〉.

ETXEZARRETA, E.; ALVEAR, A.; DÍAZ, L.; y OREGUI, L. (2016): "Informe I. Cooperativas de cuidados: de la prestación de asistencia personal hacia la colectivización de las personas cuidadoras", Gipuzkoako zaintza esparruan Ekonomia Sozial eta Solidarioko ekimenak martxan jartzeko oinarriak, shttp://www.behagi.eus/files/ informes/informe-sobre-cooperativas-decuidados-2015-gezki.pdf〉.

FANTOVA, F. (2015): “Crisis de los cuidados y servicios sociales”, Zerbitzuan, no 60, págs. 47-62, 〈http://www.zerbitzuan.net/documentos/ zerbitzuan/Crisis_cuidados_servicios_sociales. pdf〉, 〈https://doi.org/10.5569/11347147.60.04>.

FERRETI, T. (2017): "Predistribución y organizaciones igualitarias", en ZALAKAIN, J. y BARRAGUÉ, B., Repensando las políticas sociales, Madrid, Editorial Grupo 5.

FEDERICI, S. (2013): Revolución en punto cero. Trabajo doméstico, reproducción y luchas feministas, Madrid, Traficantes de Sueños, págs. 205-206.

GABA, M.R. y SALVO, I. (2016): "Corresponsabilidad en el cuidado infantil y conciliación con la trayectoria laboral: Significaciones y prácticas de varones argentinos", Psicoperspectivas, vol. 15, $\mathrm{n} \div 3$, págs. 23-33, 〈http://www.psicoperspectivas. $\mathrm{cl} /$ index.php/psicoperspectivas/article/ view/749/584'.

GIPUZKOA (2017): Decreto Foral 24/2017, de 12 de diciembre, por el que se regulan las prestaciones económicas de la Ley 39/2006, de 14 de diciembre, de Promoción de la Autonomía Personal y Atención a las personas en situación de dependencia, Boletín Oficial de Gipuzkoa, $\mathrm{n}$ 은 246, 〈https://egoitza.gipuzkoa.eus/ogasuna/ normativa/docs/o001123c.pdf〉.

- (2015): Decreto Foral 4/2015, de 3 de febrero, de Registro Foral de Servicios Sociales de Gipuzkoa", Boletín Oficial de Gipuzkoa, nํㅜㅇ, <https:// egoitza.gipuzkoa.eus/ogasuna/normativa/ docs/0001027c.pdf〉.

GRAHAM, H. (1983): “Caring: A Labour of Love” FINCH, J. y GROVES, A.: Labour of Love: Women, Work and Caring, Routledge \& Kegan Paul.
INTERSOCIAL (2016): Análisis econométrico estudio comparativo de la asistencia personal y la atención residencial, Oficina de Vida Independiente de la Comunidad de Madrid, <http://www.madrid.org/bvirtual/ BVCM013850.pdf〉.

JUBETO, Y.; LARRAÑAGA, M. y RODRÍGUEZ, A. (2017): “Presentación", Revista Ekonomiaz, nㅇ9, págs. 6-20 <http://www.euskadi.eus/webo1a2reveko/es/k86aEkonomiazWar/ekonomiaz/ abrirArticulo idpubl $=87$ \& registro $=4$ '

KELLER, C. (2017): "Hacia una agenda feminista de los cuidados" en UBASART, G.; RIUS, A.; KELLER, C.; y DOMINGUEZ, M.: "Políticas de género y calidad de vida en la ciudad", Fuehm Boletín Ecosocial, no 38 , págs. 20-27, 〈https://www. fuhem.es/media/cdv/file/biblioteca/Dossier/ Dossier-Politicas-de-genero-y-calidad-de-vidaen-la-ciudad.pdf〉.

LEÓN, M. (2009): “Cambiar la economía para cambiar la vida desafíos de una economía para la vida", ACOSTA A. y MARTÍNEZ E. (comp.): El buen vivir, Quito, Abya-Yala.

LEONARDO, J. (dir.) (2007): Los cuidados informales en la Comunidad Autónoma de Euskadi: las necesidades de las personas cuidadoras, serie Documentos de Bienestar social, $\mathrm{n}^{0} \mathbf{7 2}$, VitoriaGasteiz, Servicio Central de Publicaciones del Gobierno Vasco.

MARTÍNEZ, M. J. (2017): "El estado de bienestar y los permisos para el cuidado de la infancia en la Comunidad Autónoma del País Vasco", Revista Ekonomiaz, nํㅜ 91, págs. 246-275, <http:// www.euskadi.eus/webo1-a2reveko/es/ k86aEkonomiazWar/ekonomiaz/abrirArticulo?i $\mathrm{dpubl}=87 \&$ registro $=15$ > .

MINGUELA RECOVER, M. y CAMACHO BALLESTA, J. (2015): "Cuidados mixtos y cuidados informales a los mayores dependientes, ¿son complementarios o sustitutivos? Una visión comparada entre los países del sur de Europa", Zerbitzuan, no 58, págs. 15-25, 〈https://www.siis.net/es/ publicaciones/zerbitzuan/〉, 〈https://doi. org/10.5569/1134-7147.58.02>.

NOGUEIRA, J. y ZALAKAIN, J. (2015): “La discriminación múltiple de las mujeres extranjeras que trabajan en servicios domésticos y de cuidados a dependientes en Euskadi", Zerbitzuan, $\mathrm{n}^{\circ}$ 6o, págs. 143-162, https://www.siis.net/ es/publicaciones/zerbitzuan/, «https://doi. org/10.5569/1134-7147.60.10>.

OCDE (2015): Panorama de la salud 2015: Indicadores de la OCDE, Mejores políticas para una vida mejor, OCDE, 〈https://www.oecd-ilibrary.org/ docserver $/ 9789264270626$-es.pdf?expires $=153$ $9173299 \&$ id $=$ id $\&$ accname $=$ guest $\&$ checksum $=C$ 1658490AC4422C02B2A3FB487F32FBE).

PAÍS VASCO (2015): “Decreto 185/2015, de 6 de octubre, de cartera de prestaciones y servicios del Sistema Vasco de Servicios Sociales", Boletín Oficial del País Vasco, no- 206, <https://www.euskadi.eus/ y22-bopv/es/bopv2/datos/2015/10/1504561a. pdf>.

- (2012): "Decreto 155/2012, de 24 de julio, de Registros de Servicios Sociales", Boletín Oficial del País Vasco, n- 150, shttps://www.euskadi.eus/y22- 
bopv/es/bopv2/datos/2012/08/1203569a. pdf〉.

- (2008): “Ley 12/2008, de 5 de diciembre, de Servicios Sociales", Boletín Oficial del País Vasco, no 246, págs. 31.840-31.924, 〈https:// www.euskadi.eus/y22-bopv/es/bopv2/ datos/2008/12/0807143a.pdf〉.

PARKER, R. (1981): “Tending and social policy”, en GOLDBERG, M. y HATCH, S. (eds.): A New Look at the Personal Social Services, Policy Studies Institute, Londres, n. ${ }^{\circ}$, págs. 17-34.

PÉREZ OROZCO, A. (2017): Subversión feminista de la economía. Aportes para un debate sobre el conflicto capital-vida, Madrid, Traficantes de Sueños.
RECIO CÁCERES, C.; MORENO COLOM, S.; BORRÀS

CATALÀ, V. y TORNS MARTÍN, T. (2015): “La

profesionalización del sector de los cuidados”, Zerbitzuan, no 60, págs. 179-194, 〈https:// www.siis.net/es/publicaciones/zerbitzuan/>, 〈https://doi.org/10.5569/1134-7147.60.12〉.

UNGERSON, C. (2005): “Care, work and feeling”, Sociological Review, vol. 53, supl. 2, págs. 188-203.

UNGERSON, C. (1983): Why do Women Care? en FINCH, J. y GROVES, A.: Labour of Love: Women, Work and Caring, Routledge \& Kegan Paul, págs. 31-49. 